\title{
РАЗВИТИЕ ИННОВАЦИОННЫХ ПРОЦЕССОВ В ИНТЕГРИРОВАННОЙ ПРОМЫШЛЕННОЙ СРЕДЕ
}

Тюкавкин Н.М., профессор, Самарский университет, г. Самара, Россия Герасимов К.Б., доцент, Самарский университет, г. Самара, Россия Гоман К.И., ассистент, Самарский университет, г. Самара, Россия

Аннотация. В исследовании представлены методы и подходы, актуализирующие развитие интеграционных процессов в интегрированной промышленной среде. Основное внимание сосредоточено на исследовании вопросов, обосновывающих интеграционные структуры для осуществления инновационной деятельности, а также процессам организационнотехнологических изменений, при формировании и функционировании инновационных структур, предполагающее их адаптацию к производственной деятельности. Большое внимание в исследовании отводится формированию интеграционных структур, как основной и перспективной формы организации хозяйственной деятельности на современном этапе развития производства. Авторы анализируют характерные особенности и факторы влияния на интеграционные процессы в промышленности, предлагают новые формы интеграции. Отдельное внимание в исследовании уделено формированию кластерно-сетевых структур, являющихся основой развития процессов интеграции и сетевой кооперации в промышленности.

Ключевые слова: исследование, методы, инновационная деятельность, интеграционные структуры, промышленность, сетевизация, кластеры, кроссинновации.

Инновационные деятельность в промышленности представляет основные условия для ее эффективного и конкурентоспособного развития. За счет 
интеграция промышленных предприятий-участников инновационной деятельности, формируются условия организации, осуществления и диффузии инноваций, создаваемых при сетевом взаимодействии участников интегрированных промышленных структур, особенно кластерных образований, имеющих существенные предпосылки для инновационной деятельности.

Актуальность темы исследования определяется недостаточной степенью изученности инновационной деятельности в интегрированных промышленных структурах, а также развитием новых форм и новых организационнотехнологических структур. Данное исследование дополняет более ранние публикации по данной теме, определяет и развивает существующие научные положения, уточняет и дополняет категорийный аппарат, а также научные понятия в данной области.

Интегрированные промышленные структуры представляют определенное множество дислоцированных на территории региона или государства промышленных предприятий, осуществляющих совместную деятельность [1]. Основой производственной деятельности данных структур являются научные исследования и опытно-конструкторские разработки (НИОКР), а также их комплексное обеспечение за счет институциональной инфраструктуры. Это положение соответствует базовым понятиям для экономики государства, в связи с тем, что формирование и развитие инновационной деятельности создается за счет условий, созданных в государстве национальной и региональной инновационных систем (НИС и РИС). Инновационные системы отражают стратегические государственные, региональные и отраслевые интересы развития экономической деятельности, способствуя их трансформации в промышленное производство.

Анализируя позиции ученых по исследуемой проблеме, авторами установлено, что существующие подходы отражены и в других трудах, но в них мало внимания уделено инновационным процессам в интегрированной промышленной среде. 
Традиционно интегрированная промышленная среда представлена следующей структурой: базовое ядро, где формируется и осуществляется производственная деятельность, разрабатываются новшества; сфера НИОКР и технологической подсистемы; сфера коммерциализации новшеств и продвижения инновационной продукции на рынок; обеспечивающая инфраструктура; ресурсная база. Ряд ученых представляет инновационную интегрированную структуры как систему правовых, материальных, финансовоэкономических, социальных институтов, обеспечивающих совместную разработку и реализацию научных идей с их дальнейшей диффузией в формирование новшеств [2]. В данном представлении, инновационная интегрированная промышленная структура - это созданное определенным образом территориально-экономическое пространство, которое обеспечивает создание инноваций в интересах региона и государства [3].

Другие исследователи, такие как Н.В. Сироткина, А.В. Поляков, А.В. Поляков, М.В. Филатова под инновационная интегрированной промышленной средой понимают: государство, бизнес, общественные институты, НИОКР и пр., создающие и обеспечивающие производство инноваций и их диффузию [4].

Но основе данных положений авторами, для осуществления дальнейших исследований, предлагаются пояснения по инновационной интегрированной промышленной среде, организационно являющейся элементом РИС и НИС. Отсюда следует, что специфика инновационной интегрированной промышленной среды заключается в формировании и развитии инновационной деятельности и повышению ее эффективности [5, 12].

C учетом вышесказанного, авторами уточняется определение инновационной интегрированной промышленной среды, как основного условия для инновационной деятельности промышленного сектора: инновационная интегрированная промышленная среда - это организационная и технологическая стабильность организации промышленной деятельности, выражающейся во внешнем и внутреннем инфраструктурном обеспечении 
промышленных предприятий, на базе создания и применения потенциальных инноваций.

Материалы и методы. Базовыми предпосылками для развития инновационных процессов и формирования новой добавленной стоимости выступает инновационная интегрированная промышленная среда, представляющая основное содержание производственных целей и культуру труда, направленных на генерирование инноваций [6, 11]. «Особенностями инновационной интегрированной промышленной среды является ее предпосылки для генерирования синергии, увеличения добавленная стоимости, которая формируется не путем суммирования эффектов, получаемых от нового набора элементов, представленных в данной среде, а из новых способов организации их взаимодействия» $[7,10]$.

Инновационная интегрированная промышленная среда содействует эволюции промышленных структур, создаваемых в формах промышленных кластеров, технополисов и технопарков, которые концентрируют вокруг себя инновационно-активные предприятия [8,9].

По мнению авторов, для реализации целей социально-экономического развития государства и создания условий для инновационного развития промышленности, промышленную интеграцию необходимо осуществлять на основе инновационных кластеров, представляющими современные тренды развития инновационной интегрированной промышленной среды. Данные кластеры, по своему содержанию, уже сами являются инновационной интегрированной промышленной средой, реализуя направления развития инновационной деятельности, с учетом технологического и инфраструктурного обеспечения.

Результаты исследований. В заключение авторами приводятся следующие результаты исследования:

1. Уточнено содержание и определение инновационной интегрированной промышленной среды, как важнейшего условия для реализации инновационной деятельности - это организационная и технологическая стабильность 
организации промышленной деятельности, выражающейся во внешнем и внутреннем инфраструктурном обеспечении промышленных предприятий, на базе создания и применения потенциальных инноваций.

2. Раскрыты и предложены новые формы промышленной интеграции технополисы, технопарки, инновационные кластеры, как потенциальные структуры для производства инноваций.

3. Раскрыто содержание кластерно-сетевой организации промышленных предприятий.

Обсуждение полученных результатов. Авторы предложили и подтвердили гипотезы, представляющие следующие положения: целью интеграционной деятельностью в инновационной интегрированной промышленной среде выступает условие по переводу предприятий в устойчивое состояние функционирования; интеграция промышленных предприятий требуют поиска новых форм и способов, которые влияют на создание инноваций; интеграция промышленных субъектов предполагает их адаптацию к существующим запросам внутренней и внешней среды.

Выводы. Исследование носит теоретическое и практическое значение: оно представляет рекомендации для развития инновационных процессов в интеграционной промышленной среде.

\section{Список используемых источников}

1. Баринов В.А. Разработка системы оценки качества инновационной среды региона (на примере Санкт-Петербурга): дисс. ... канд. экон. наук. СПб., 2014. 118 c.

2. Евсеенко А.В., Зверев В.С., Унтура Г.А. Интеграционные процессы в экономике региона. Новосибирск: ИЭиОПП СО РАН, 1996. 196 с.

3. Кобзева А.Г., Ченцова Е.П. Инновационная среда: теоретический обзор исследований // Казанская наука. 2014. №12. С. 77-79. 
4. Липатов А.А. Европейская цивилизация как дифференцированная целостность // Мировая экономика и международные отношения. 2007. № 6. C. 16-20.

5. Поляков А.В., Сироткина Н.В., Филатова М.В. Интеграционные процессы в инновационной среде региона: новое в теории и практике // Вестник Белгородского университета кооперации, экономики и права. 2015. № 4 (56). C. 190-198.

6. Ревякин Е.В. Инерция интеграции как одна из особенностей ее динамики // Мировая экономика и международные отношения. 2006. №7. С. 37.

7. Чебыкина М.В., Шаталова Т.Н. Методологические подходы к формированию управленческих инновационных процессов промышленных предприятий // Вестник Самарского университета. Экономика и управление. 2021. T.12. №1. С. 116-122.

8. Andersson T., Serger S.S., Survik J., Hansson E.W. The cluster policies whitebook. IKED, 2004.- Malmö, Sweden, 2004. - 252 p.

9. Asheim B.T., Isaksen A. Location agglomeration and innovation: Towards regional innovation systems in Norway. Step group. Report 13-96, Oslo, 1996. 64p.

10. Bergman E.M., Feser E.J. Industrial and Regional Clusters: Concepts and Comparative Applications. - Regionl Research Institute, WVU, 1999.

11. Edquist C. Systems of innovation: Perspectives and challenges, in Fagerberg, J., Mowery, D. and Nelson R. (eds) // The Oxford Handbook of Innovation N.Y., 2006. - P. 181-208.

12. Freeman, R. E. Strategic Management: A Stakeholder Approach. GB: Cambridge university press, 2010. - 292 p.

(c) Тюкавкин Н.М., Герасимов К.Б., Гоман К.И. 2021 г. 